\title{
Situação de Miguel Reale
}

\author{
José Guilherme Merquior
}

A Evaristo de Moraes Filho

Apresentação de CELSO LAFER

\begin{abstract}
Completou 80 anos, plenos de vigor intelectual, no dia 6 de novembro de 1990, o prof. Miguel Reale. Duas vezes reitor da USP e professor emérito da Faculdade de Direito, na qual foi catedrático de Filosofia do Direito, de 1940 a 1980, a sua obra e o seu magistério mereceram e receberam justas homenagens. Entre elas, o IV Congresso Brasileiro de Filosofia do Direito, que teve como tema básico o seu pensamento e que foi realizado em João Pessoa de 9 a 15 de dezembro, graças ao apoio e à iniciativa do governador Tarcísio Burity, bem como o livro de estudos em homenagem a Reale, que Tércio Sampaio Ferraz Jr. e eu estamos terminando de organizar. Deste livro está sendo destacado, para a Revista USP, que assim se associa às comemorações dos 80 anos de Miguel Reale, o ensaio inédito de José Guilherme Merquior. Trata-se, infelizmente, do último escrito de maior amplitude de José Guilherme, que faleceu em janeiro deste ano, empobrecendo o cenário intelectual brasileiro e internacional pelo muito que tinha a fazer e realizar. A publicação do ensaio de José Guilherme é assim, também, um preito à sua memória, que evoco com imensa saudade e fraternal amizade e admiração.
\end{abstract}

Tudo o que vou dizer aqui tem mero valor de anotação, não me sendo infelizmente possível fundamentar e desenvolver melhor estas observações sobre o iter filosófico de Miguel Reale. O propósito é "situá-lo", orteguianamente, isto é, discernir na sua trajetória de pensador um laço, mais elástico do que tenso, com sua circunstância de brasileiro em formação entre 1930 e 50, e desde aí firmado como um dos poucos filósofos latino-americanos capazes de se imporem à consideração ocidental. E todavia, desde Hegel, desde Nietzsche, desde Croce e do próprio Reale, sabemos que essa "situação" tem de ser entendida em sentido forte, não sendo para nada irrelevante "quem" o situa, nem "quando" nem "por que": o que se vai ler é, fatalmente, portanto, em ampla medi$\mathrm{da}$, o produto de um contraste generacional de perspectivas.

Como primeira nota, reparo que, em Reale, o filósofo parece ter emergido do pensador político. Sua incisiva obra de juventude, $\boldsymbol{O}$ estado moderno (1934), mostra-nos o paulista recém-escaldado da luta constitucionalista de 32 às voltas com o neo-estatalismo fascista. À estatolatria fascista, ao estado totalitário de Gentile, Reale contrapõe um estado cơrporativo inserido na tradição católico-integrista. A leitores franceses, teríamos que explicar a diferença dizendo-o mais perto de Maurras que de Mussolini. $O$ es-
JOSÉ GUILHERME MERQUIOR (1941-1991) foi ensalsta. Seu último cargo foi o de embaixador do Brasil junto à Unesco. Tem uma obra vasta, que compreende interesses literários, pollticos, sociológicos e filosóficos. Alguns de seus livros são Formalismo e tradição moderna, $A$ estética de Lévy-Strauss (Editora Tempo Brasileiro), Astúcias da Mimese e $\mathrm{O}$ elixir do apocalipse (Nova Fronteira). Seu livro sobre Michel Foucault foi publicado na Inglaterra na série "Modern Masters", da Editora Fontana. Seu último livro publicado no Brasil, Crnica (Nova Fronteira), é uma antologia pessoal de seus escritos. 
tado moderno revela admiração pelo duce, mas também pelo intervencionismo anti-Depressão de Roosevelt. Usa várias vezes o teórico fascista oficial, Alfredo Rocco, mas não se esquece de render tributo a Jellinek, cuja "grande superioridade", na teoria do estado, fora a de "salvaguardar a autonomia dos indivíduos"(1) graças à sua doutrina dos direitos públicos subjetivos. Em suma, se o jovem Reale não vacila em conjurar "um governo forte, um profundo sentimento de hierarquia e de disciplina"(2), desconfiando sempre da espontaneidade social como fonte da ordem e caricaturando passavelmente o legado liberal (reduzido a "liberalismo lírico"), o certo é que seu integralismo, como o de Plínio Salgado, faz questão de arrimar-se na axiologia cristã, com sua alta apreciação "metaburguesa" do indivíduo, e de descartar o estado totalitário, "absorvente, mecanicamente unitário"(3) em prol de um "estado integral" grupalista, apoiado na autêntica participação de associações profissionais.

De resto a teorização de $O$ estado moderno vinha desenvolver as idéias esboçadas num opúsculo de 1933, "A posição do integralismo"; e nesse trabalho, Reale, criticando o cesarismo fascista, pregava um estado novo "de baixo para cima" e buscava uma terceira via entre liberalismo e socialismo mais inspirada no projeto modernizador-autoritário de Alberto Torres do que em qualquer ideólogo europeu de direita. A prova é que, publicado o texto, romperia com o integralismo brasileiro a sua ala "salazarista", sediada em São Paulo(4).

No fundo, o jovem Reale foi uma espécie de Duguit que preferia o estatismo ao iberal-solidarismo. Não desgosta completamente de Gentile, mas tampouco de Carlo Rosselli e do seu "liberalismo social". Autoritário-corporatista, a tendência de seu pensamento não coincide com o estatismo violento do fascismo, assim como será totalmente infensa ao racismo nazista.

O exílio romano, após o fracasso do golpe integralista de 38 , abriu a Reale os horizontes da filosofia do direito e da filosofia tout court. Do militante político, cedo desiludido, in loco, pelo fascismo, emergiria o pensador, numa reflexão bem mais abrangente e aprofundante que a das obras juvenis, malgrado a erudição e segurança de raciocínio já nelas manifestadas. Na Itália Reale descobre o alcance do historicismo de Croce, do institucionalismo de Hauriou, do relacionismo de Del Vecchio e da Rechtsphilosophie de Radbruch. Del Vecchio lhe ensina a discernir no direito um substrato de experiência intersubjetiva: é o tema da alterità. Mas é o weberiano Gustav Radbruch quem catalisa a sensibilidade realiana para o motivo da relação direito/valor. Colega e amigo de Max Weber em Heidelberg, Radbruch sabia que um conceito objetivista de justiça, como o de Stammler (bête noire do próprio Weber) não era fundamental. Porém, ao mesmo tempo não desejava proceder como o formalismo de Kelsen, dissociando pura e simplesmente a teoria do direito de uma doutrina dos valores. Os valores, para ele e Weber, eram matéria de consciência e não de ciência: Gewissen, em vez de Wissenschaft. Como Weber, Radbruch dramatizava a Wertbeziehung de Rickert, a famosa relação (neokantiana) com o valor, numa atenção especial à tensão e ao conflito intra e interaxiológico. Mais tarde, a difícil conversão neojusnaturalista de Radbruch não deixará de interessar Reale. Mas ao findar a agitada década de 30, é esse neokantismo que o atrai. Só que alguns comentaristas esquecem algo decisivo: a inclinação weberiana do neokantismo, isto é, da axiologia da Radbruch.

Aqui faço uma pausa para uma nota intuitiva e impressionística, e que no entanto creio preciosa para a captação da forma mentis do pensar de Reale. Enquanto Weber e Radbruch são pensadores da fratura, da antinomia e do conflito, outra me parece a conformação de base da reflexão de Reale. Ele vê, por conseguinte, a relação com os valores numa vivência menos agônica, mais plácida e confiante do que a dos dois torturados mestres de Heidelberg. Até certo ponto, embora sem recaída na ilusória harmonia do Zeitgeist compacto, Reale recupera o senso do fluxo majestoso da História, criando épocas a partir de novos feixes axiológicos, hegemônicos, senão homogêneos. E por trás dessa ótica, perfila-se claramente uma "sensibilidade" hegeliana. Ela é que levou Reale, ao reagir à axiologia, a impregnar de historicidade a sua versão do vínculo direito/valor. Conforme se sabe, a conceituação desse tema, alcançada por volta de 1940 , constitui a pedra basilar da jurisfilosofia realiana, a célebre "teoria tridimensional do direito", focalizando o fenômeno jurf́dico como a um só tempo fato, valor e norma. Mas o que o não-jusfilósofo sente, pulsante sob essa concepção magistral, e a velha "paixão pelo universal concreto", nas palavras do próprio Reale. Paixão que dimana da recorrente influência da Fenomenologia do esplrito. 
Quem diz Hegel, nesse ponto, diz realismo sociológico e amor à concreção. E aqui reside, julgo eu, a raiz filosófica da dupla rejeição realiana do juspositivismo formalista (Kelsen) ou da bizarra tentativa de síntese existencialo-kelseniana na obra fulgurante do argentino Carlos Cossio. Do lado de Kelsen, Reale dá por falta do elemento subjetivo in actu, que é historicidade engatilhada, deflagração pura dos processos comunicacionais que asseguram a continuidade ou promovem a mudança, em escala socialmente significativa. Do lado de Cossio, o problema se converte nas deficiências da liberdade abstrata. Vários anos depois, em Pluralismo e liberdade (1963), Reale condenaria o mito existencialista da liberdade absoluta, puramente indeterminada.

É claro que, para Cossio, com a aprovação de Reale, o direito é "conduta" e, portanto, algo irredutível ao normativismokelseniano. Mas o problema é que o fático, tão acentuado na teoria de Cossio, justamente também pode limitar nossa compreensão do plexo sociojurídico ao restringir-se, no estudo da sentença como estrutura da validade legal, "às experiências axiológicas já verificadas, e não às meras experiências jurídicas posstveis"(5). Ou seja: a existencialização da experiência jurídica pode pesar tanto por abstrativismo egológico quanto por concretismo míope, porque inocente da historicidade maior do universal concreto, sempre em marcha e mudança.

Experiência - eis uma palavra nuclear no pensamento de Reale. Pode-se dizer que toda a sua fundamentação do direito, do estado e da liberdade, seus três temas principais, representa um esforço de analítica da experiência em sentido metakantiano. Kant nos deu o mapa cognitivo, por assim dizer, da experiência natural. Reale recorre a Vico e Husserl - especialmente o último Husserl, o da Krisis - para legitimar a experiência "como cultura". Daŕ seu grande livro de 1977, Experiência e cultura. A ida a Husserl ê uma garantia “ontognoseológica", como diz o próprio autor: é uma preocupação de ordem eminentemente epistemológica, como tal de ascendência claramente kantiana e por isso mesmo servindo de repoussoir à hubris da historiosofia hegeliana, que não raro(6) zomba do escrúpulo kantiano em examinar o instrumento (a cognição) antes de empregá-lo. Reale reconhece que não é possível dar as costas ao cuidado epistemológico.

$\mathrm{O}$ que ele almeja é começar a cartografia de uma Lebenswelt jurídica, uma experiência pré-categorial ou antepredicativa do direito in fieri. Para tanto, há que retornar à meditação fenomenológica sobre a intencionalidade e o "a priori materia!", assim como, logicamente, as éticas de Schaler e Hartmann - este último, com suas estratificações ontológicas, um referencial constante do Reale maduro. Porém os valores não são, para Reale, objetos ideais - são objetos autônomos. Isso, por si só, denota a marca do universal concreto. Reale ê um Husserl da cultura, mas é igualmente um Hartmann hegelianizado, na medida em que - precisamente - fortemente historicizado. Experiência e cultura trata com visível antipatia a noção hartmanniana de um "espírito objetivado", distinto do espírito objetivo, que é vivente e intersubjetivo, ao passo que aquele é um conjunto mais ou menos pétreo de regras e códigos (um equivalente do "mundo 3" de Popper).

A denúncia da "talta"(7), ou, digamos, do déficit da historicidade em Hartmann e mesmo, a rigor ${ }^{(8)}$, no último Husserl ê profundamente característica de Reale. Meio século atrás, resenhando a Introdução à filosofia da história de Aron, Bernard Groethuysen notava que a diferença entre seu mestre Dilthey e o jovem Aron é que Dilthey não pedia explicações à histớria, até porque "não se interroga a vida", enquanto para Aron
5 M. Reale. Horizontes do direito e da historia. 2nd. ed., Saraiva, 1977, p. 293.

6 Cf. Hegel, Enciclopédia, p. 10.

$7 \mathrm{M}$. Reale, Experiência e cultura, p. 233.

8 Idem, p. 131. 
havia "um porquê da história", um empenho presentista em decifrar o drama do destino. Mas Aron, nesse aspecto, weberiano medular, limita-se a dramatizar o "historismo" - a consciência da irrepetível especificidade do histórico - sem tergiversar com o "historicismo" - a busca generalizante do "sentido" (conquanto não necessariamente de "leis") da História. Weber foi um "historista" (embora sem os cacoetes irracionalistas do Historismus, segundo procurei mostrar em meu livro Rousseau e Weber(9)); Hegel, um "historicista". De que lado devemos colocar Miguel Reale?

Creio que, tranqüilamente, no campo historicista. Reale não hesita, aliás, em dissentir de um tabu historista, o mito da historiografia como saber ideográfico, sempre individualizante. Reale(10) adverte que os bens culturais são repetíveis e que, logo, a análise histórica não saberia ser prisioneira do único irredutível, por mais que a descrição especificante tenha lugar de maior relevo na interpretação histórica. Outro indício do historicismo realiano: seu conceito de "patamares" axiológicos ou epocais, quem sabe ligado àquele "sentido de carência" que, em Pluralismo e liberdade, compele o homem a prosseguir, quando nada por sua radical insatisfação, a abertura cumulativa que chamamos processo histórico.

Tornou-se comum descrever a posição filosófica de Reale como um "culturalismo". Não gosto muito das conotações neoidealistas do termo. E observo que o próprio Reale não parece assim tão afeiçoado a tal etiqueta. Para começar, descreve o culturalismo como seu ponto de partida mais que de chegada. Seu último livro, Nova fase do direito modernd"11) esclarece: "Meu pensamento Tornou-se comum descrever a (...) evoluiu de uma compreensão do direito posição filosófica de Reale

como um "culturalismo".

Não gosto muito das

\section{conotações neoidealisłas do}

termo. E observo que o

próprio Reale não

parece assim afeiçoado

a tal etiqueta

meu ver bem mais precisa com da natureza e da evolução do pensar do mestre de Fundamentos do direito (1940) e Verdade e conjetura (1983).

Entre as aquisições realizadas pela radicalização heideggeriana da fenomenologia, Reale arrola ${ }^{(14)}$ a enfática afirmação da temporalidade e historicidade do homem. Todavia, como têmpera filosófica, estimo seu pensamento bem mais próximo do existencialismo de Jaspers do que dos diktats oraculares da ontologia fundamental. Subjacente à longa perquirição heideggeriana acerca do Ser acha-se um "niilismo interior" (K. Loewith), uma descrença intima disfarçada em demanda fundamentalista de um Graal ontológico. A tonalidade ética de Jaspers é outra, feita de absolutos inapreensfveis e não obstante intuf́os em situações-limite por indivíduos weberianos, isto é, menos dados ao niilismo integral que às tensões implícitas no "politeŕsmo dos valores". Jaspers permanece um humanista; mas um humanista que, escrevendo após Nietzsche, sabe que "qualquer imagem do homem é insuficiente". Reale cita essa mesma frase-chave(15). De minha parte, aposto que, entre as imagens insuficientes, ele não se oporia a que inclú́ssemos o mito fundamentalista do homem "pastor do Ser", figura arcádica e arcaica de repúdio tecnofóbico à alta modernidade e, o que é ainda pior, alérgica aos valores da democracia e do individualismo.

Tocado por Heidegger, mas sem ser medularmente heideggeriano, Reale escapa desse modo ao elemento criptohegeliano no mestre da Floresta Negra - o seu holismo "epocal". A preocupação de Reale, ainda aqui ecoando Jaspers ${ }^{(16)}$, é distinguir totalidades 
concretas não-holistas. Noutro passo da mesma obra(17), ele critica o hegelianismo porque, nas sínteses progressivas do Espírito Objetivo e do Espítiro Absoluto sacrifica-se a singularidade do empírico. Em conseqüência, diz Reale parodiando Vico, "o factum não se converte no verum, mas, em última análise, neste se dissolve". É como se o nosso pensador receasse ver a problemática do Absoluto (ou do Ser) evacuar a rica textura do espírito objetivo. Como todo (semi)hegeliano de valor, Reale despreza o Absoluto e se concentra na colonização conceitual do mundo da cultura, ou seja, do espírito objetivo.

III

Hâ em Miguel Reale, a meu ver, dois otimismos filosóficos, de valor desigual. O primeiro nos fala dos valores, que o filósofo tende a conceber como complementares e solidários entre $\mathrm{si}^{(18)}$. Sinceramente, julgo esse harmonismo pouco verossímil. A visão weberiana de um antagonismo dos valores (com ou sem a heterogenia meio-fim, sublinhada desde Wundt) me parece mais próxima da realidade. Como a sociedade, a cultura vive em conflito - até certo ponto, do conflito - e a sociologia liberal tem o mérito de reconhecê-lo. O sonho neocatólico de uma re-harmonização dos valores não se afigura capaz de enraizamento na cultura moderna. O pluralismo, que Reale sublinha, não leva ao consenso; a dissonância é inerente à sociedade aberta e, tudo indica, à alma contemporânea.

O segundo otimismo vai mais fundo. Trata-se daquilo que para Windelhand, nas páginas finais de sua monumental História la filosofia, aponta como uma fidelidade secreta de Nietzsche ao idealismo alemão: a idéia de uma elevação, ou melhoramento; do tipo humano através da filosofia. Esse belo postulado idealista é de fato comum a Fichte, Schelling, Hegel e Nietzsche, lancando uma ponte entre este e a filosofia nórdica anterior ao humanismo pessimista le Schopenhauer ou o doloroso misticismo truncado de Kierkegaard. Ora, Reale se insere nessa linha moral, que ainda repercute 'm Husserl, porém não em Heidegger. Não

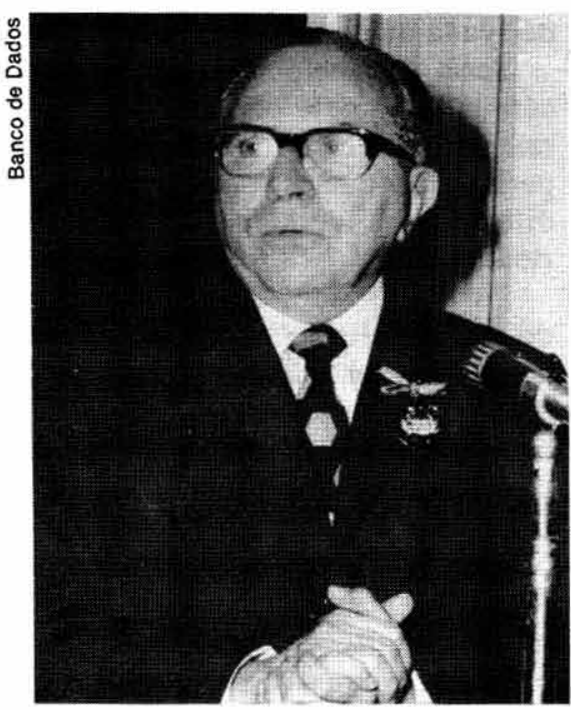
é à toa que o Hegel da escola de Frankfurt, Habermas, é o filósofo otimista do presente, ^o passo que o chefe do heideggerianismo pós-estruturalista, Derrida, encarna o pólo sposto. Sem a menor dúvida, Reale forma entre os otimistas, pela letra e pelo espírito de sua obra. Seu humanismo é anagógico; seu niilismo, nenhum.

Reale é hoje senhor de um pensamento que, sem ser de modo algum a priori antime‘físico ${ }^{(19)}$, se recusa ao irracionalismo. Sem ser íntimo da filosofia analítica, pois que ıreqüentando mais Husserl e Hartmann do que Wittgeinstein ou Quine, o mestre de São 'aulo se manteve sabiamente ao largo da triste deriva "misológica" do pensar contemnorâneo. Nem pactua com a auto-indulgência do desconstrucionismo, ou com o extremo .elativismo de Rorty, Vattimo ou Lyotard.

A melhor maneira de situar sua obra talvez consista numa comparação entre seu hissricismo axiológico e outros dois filósofos-humanistas do nosso tempo: Croce e Ortea. Como ambos, Reale pratica uma filosofia de intervenção, isto é, engajada nos combates ético-políticos (para empregar uma categoria cara a Croce) da modernização aliana, espanhola, brasileira. Estilisticamente, Reale está mais próximo de Croce que 'e Ortega, porque neste o ensaísmo predomina como órgão do pensar. Como Croce, Keale não é mais propriamente um pensador sistêmico, mas permanece sistemático.

Seu maior potenciamento reflexivo, nesse plano sistemático, ocorre na filosofia do tireito e não em sínteses historiográficas, como no Croce da maturidade. E à diferença ueste, Reale é um espírito impregnado de historicidade sem ser um historiólogo (a Cro-
Miguel Reale
17 Idem, p. 189.
18 Nova fase, p. 50.
$19 \mathrm{Ct}$. Verdade e conjetura, caps. IV e V.

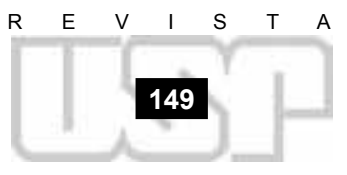


20 Rusconi, 1990.

21 B. Croce, La Ricerca della dialletica, 1975.

22 "La Lebenswelt e Pauto-constituzione della natura", in Filosofia 89 , org. por Gianni Vattimo, Laterza, 1990.

23 Cf. C. Lafer. A reconstrução dos direitos humanos, São Paulo, Companhia das Letras. 1988, p. 228.

24 Cr. B. Croce, Indagini su Hegel, 1952.

25 Experiência e cultura, p. 227. ce devemos, aliás, o uso positivo de "historicismo", palavra sem isso desmoralizada pela crítica popperiana; do historicismo e não só do historismo, tendência alemã, de Ranke e Meinecke, que Croce a um só tempo incorporou e superou, como visão filosófica).

Prospera atualmente na Itália um certo retorno a Croce, de que o volume de Raffaello Franchini, Giancarlo Lunati e Fulvio Tessitore, Il Ritorno di Croce nella cultura italia$n a^{(20)}$ é um belo exemplo. Pois bem: voltando a Croce, é impressionante o número de paralelos ou analogias que se podem traçar entre ele e Reale. Nunca, que eu saiba, professou este último qualquer tipo de croceanismo integral. Mas vejamos, só de relance alguns elementos ou posições comuns: 1) o antipositivismo; 2) o uso seletivo, porém crucial, de uma angulação hegeliana (ciò che è vivo e ciò che è morto nel pensiero di Hegel, para citar o famoso livrinho de Don Benedetto); 3) a impostação ético-política e. historicamente, a circunstância de que ambos os pensadores procuraram enfrentar a crise do liberalismo clássico; 4) o reconhecimento, mais ou menos explícito segundo cadá filósofo, de que não existe um problema fundamental da filosofia, mas uma infinidade de problemas filosóficos surgindo do processo histórico - posição, essa, o mais antiheideggeriana do mundo; 5) "historicismo absoluto" (Croce) num sentido em que nem : história é o absoluto (Hegel) nem o absoluto é a história, conforme as oportunas elucidações de Gennaro Sasso(21); e 6) o binômio humanismo-pluralismo.

Como quer G. Lunati, Croce deve ser visto principalmente à luz de uma tradiçãc humanística, bem mais (e seria esse o caso, aqui sim, de Gentile) do que como uma obra derivada da metafísica idealista.

Seria conveniente articular essa disjuntiva, humanismo-idealismo, com a crítica re cém-movida pelo percuciente filósofo americamo Stanley Rosen(22), ao retorno "pré-socrático" do Desejo da Origem, traço arcaico e regressivo que Rosen detecta no heideg gerianismo e suas seqüelas: a origem como fundamento, ou a celebração-dissolução dr diferença na identidade (filosofia da origem, tout en disant le contraire, como em Derrida).

Por outro lado, é lícito estender a dicotomia de Rosen, apontando-se na persistênciə do "originalismo" ou fundamentalismo uma posição intelectual alheia, quando nãı hostil, ao senso da pluralidade e do diálogo na vida social. E o problema se deixa ver $e$ parte objecti ou ex parte subjecti, ou seja, do ponto de vista da consciência ético-política. Em seu belo estudo sobre Hannah Arendt, Celso Lafer lembra que Arendt se distanciou do contratualismo social de Rousseau e Kant na medida em que, para ambos, fundamento da obrigação política é a auto-obrigação dos pactários. A fim de sublinhar o substrato da interação na experiência contratualista, Arendt preferiu, em Crisis of th. Republic, acentuar a versão "horizontal" do contrato social em Locke - o famoso par tum societatis ${ }^{(23)}$. A meu juízo, essa é também a propensão da política de Reale, desde os dias juvenis de seu corporativismo idealizado até os dias maduros de sua reflexã. sobre a inerência do pluralismo à liberdade moderna.

O próprio Croce considerava sua a tarefa de tirar da filosofia seu caráter "teológico", fazendo-a sempre mais humanística(24). Não vejo outro caminho para aquela "con preensão plural do processo histórico" com que Reale identifica seu historicismo axir lógico ${ }^{(25)}$. Fora daí, a neo-escolástica, ontológica ou desconstrucionista, logo prevalece, fornecendo ao filósofo "professoral" mais que profissional (R. Franchini) o álibi c jargão e o cultivo obscurantista da seita. Felizmente Miguel Reale aí está, no viço do sua velhice, para zelar pela historicidade concreta, a autotranscendência da cultura e . meridianidade do discurso filosófico autêntico, num espírito humanisticamente voltac para o aperfeiçoamento não-moralístico do bicho homem. Dele podemos dizer, em tributo aos seus esplêndidos oitent'anos, o que o Poeta afirmou de seu mestre Brunetı Latini:

\footnotetext{
"la cara e buona imagine paterna

di voi quando nel mondo ad ora ad ora m'insegnavate como l'uomo s'etterna."
}

(Inf., XV, 83-85)
$\mathrm{R}$

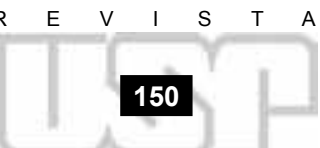

Março

Abril

Maio

1991 